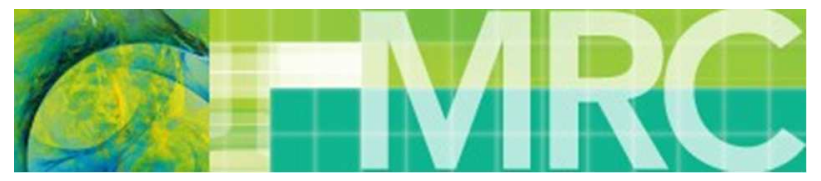

\title{
Solid-state NMR tools for the structural characterization of POSiSils: 29Si sensitivity improvement with MC-CP and 2D 29Si-29Si DQ-SQ at natural abundance
}

\begin{tabular}{|r|l|}
\hline Journal: & Magnetic Resonance in Chemistry \\
\hline Manuscript ID & MRC-18-0106.R1 \\
\hline Wiley - Manuscript type: & Research Article \\
\hline Date Submitted by the Author: & n/a \\
\hline Complete List of Authors: & $\begin{array}{l}\text { Smet, Sam; Katholieke Universiteit Leuven Centrum voor } \\
\text { Oppervlaktechemie en Katalyse } \\
\text { Verlooy, Pieter; Katholieke Universiteit Leuven Centrum voor } \\
\text { Oppervlaktechemie en Katalyse } \\
\text { Saidi, Fadila; Institut Lavoisier de Versailles (ILV), UMR CNRS 8180 } \\
\text { Taulelle, Francis; Katholieke Universiteit Leuven Centrum voor } \\
\text { Oppervlaktechemie en Katalyse } \\
\text { Martens, Johan; Katholieke Universiteit Leuven Centrum voor } \\
\text { Oppervlaktechemie en Katalyse } \\
\text { Martineau-Corcos, Charlotte; Institut Lavoisier de Versailles (ILV), UMR } \\
\text { CNRS 8180, }\end{array}$ \\
\hline Keywords: & $\begin{array}{l}\text { NMR Crystallography, polyoligosiloxysilicone, POSiSils, DQ-SQ NMR, MC-CP } \\
\text { MAS }\end{array}$ \\
\hline
\end{tabular}

\section{SCHOLARONE ${ }^{\text {TN }}$ \\ Manuscripts}




\title{
Solid-state NMR tools for the structural characterization of POSiSils: ${ }^{29}$ Si sensitivity improvement with MC-CP and $2 \mathrm{D}^{29} \mathrm{Si}^{29} \mathrm{Si} \mathrm{DQ}-\mathrm{SQ}$ at natural abundance.
}

Sam Smet, ${ }^{a}$ Pieter Verlooy, ${ }^{a}$ Fadila Saïdi, ${ }^{b}$ Francis Taulelle, ${ }^{a, b}$ Johan A. Martens, ${ }^{\text {a }}$ Charlotte Martineau$\operatorname{Corcos}^{*, b, c}$

a. Centre for Surface Chemistry and Catalysis, KU Leuven, Celestijnenlaan 200F Box 2461, B-3001 Leuven, Belgium.

b. MIM, Institut Lavoisier de Versailles (ILV), CNRS UMR8180, Université de Versailles SaintQuentin en Yvelines (UVSQ), 45 avenue des États-Unis, 78035 Versailles Cedex, France.

c. CEMHTI, CNRS UPR3079, 1D avenue de la recherche scientifique, 45071 Orléans Cedex 2, France.

Corresponding author : charlotte.martineau@uvsq.fr

Keywords: polyoligosiloxysilicone - POSiSils - DQ-SQ NMR - MC-CP - ${ }^{29}$ Si NMR - NMR Crystallography

\begin{abstract}
The ${ }^{1} \mathrm{H}^{29} \mathrm{Si}$ multiple-contact CP (MC-CP) MAS NMR experiment is evaluated for the class of silicatesiloxane copolymers called Posisils, i.e. polyoligosiloxysilicones. It proves a reasonably good solution to tackle the challenge of recording quantitative ${ }^{29} \mathrm{Si}$ NMR data in experimental time much reduced compared to single pulse acquisition. In a second time, we report ${ }^{29} \mathrm{Si}^{29}{ }^{29} \mathrm{MC}-\mathrm{CP}$ double-quantum single-quantum (MC-CP-DQ-SQ) NMR experiment, which provides information about the through-space proximities between all silicon species despite the high degree of heterogeneity of this material. This work furthers the NMR tools for NMR Crystallography for inorganic polymers, as it covers flexible polymers with different dimensionalities and long/heterogeneous relaxation characteristics at low ${ }^{29} \mathrm{Si}$ natural abundance.
\end{abstract}




\section{Introduction}

NMR crystallography ${ }^{[1,2]}$ aims at assisting the structure resolution of solids by providing topological network organization and when the crystal is not rigorously periodic, information about distribution of local environments. Using a combination of X-ray diffraction, solid-state NMR and firstprinciples calculations, NMR crystallography can provide the structure of inorganic or porous solids, ${ }^{\text {[-5] }}$ which could not have been solved using any of these techniques independently. This approach is of growing interest as attested by the increasing number of articles and special issues dedicated to the method. ${ }^{[6]}$ It was further shown that such an approach could be applied to determine the structure of organic polymers, ${ }^{[7]}$ presenting short-range order and topological long range order but lacking periodicity that would make them amenable to X-ray diffraction methods, and later for silicon-based materials. $^{[8]}$

Recently, we reported a new class of copolymers, called POSiSils, polyoligosiloxysilicones, build up by linking double four ring (D4R) cyclosilicate oligomer $\left(\mathrm{Si}_{8} \mathrm{O}_{12}\right)$ with dimethylsiloxane fragments. The structure of the first material of this family, called PSS-1 (Fig. 1), a one dimensional network, ${ }^{[9]}$ could be determined from ${ }^{29} \mathrm{Si}$ single-pulse and ${ }^{29} \mathrm{Si}^{29} \mathrm{Si} \mathrm{DQ}-\mathrm{SQ}$ NMR spectroscopy assisted by computational modeling. A second material, PSS-2 (Fig. 1), a 3-dimensional network, was lately prepared, ${ }^{[10]}$ whose structure resolution turned out much more challenging than for PSS-1 due to unfavorable NMR properties (very contrasted and potentially very long relaxation times). Therefore, this study reports a set of NMR acquisition schemes to overcome such limitations. First, an evaluation of the ${ }^{1} \mathrm{H} \rightarrow{ }^{29} \mathrm{Si}$ multiple-contact cross-polarization (MC-CP) ${ }^{[11]}$ for quantitative measurements is reported. In the second part, an improved version of the ${ }^{29} \mathrm{Si}^{29} \mathrm{Si}$ double-quantum single-quantum (DQ-SQ) MAS NMR experiments, taking advantage of MC-CP magnetization transfer, more adapted to POSiSils in general, is proposed. Equipped with such methods it becomes possible to provide key information which, 
combined with other experimental data and modeling tools, would allow us to generally tackle the structure of POSiSils.

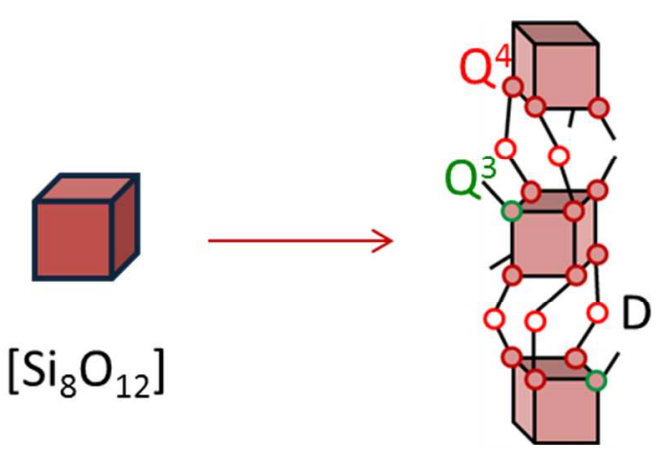

PSS-1

Fig. 1. Schematic representation of the D4R unit (left) and the resulting PSS-1 copolymer (right).

\section{Experimental section}

Synthesis

The synthesis, physico-chemical and structural characterization of PSS-2 are beyond the scope of this NMR-focused paper and will be reported in details elsewhere. ${ }^{10}$

\section{Solid-state NMR}

The 1D MAS NMR spectra of PSS-2 materials were recorded at static magnetic field of $7 \mathrm{~T}$ on an Avance III Bruker NMR spectrometer in Leuven. At this field ${ }^{1} \mathrm{H}$ resonates at $300 \mathrm{MHz}$ and ${ }^{29} \mathrm{Si}$ at 59.6 $\mathrm{MHz}$. Samples were packed in $4 \mathrm{~mm}$ outer diameter zirconia rotors and spun at $5 \mathrm{kHz}$. The ${ }^{1} \mathrm{H} \rightarrow{ }^{29} \mathrm{Si}$ cross-polarization (CP) was achieved by applying radio-frequency (RF) pulses of 60 and $50 \mathrm{kHz}$ on ${ }^{1} \mathrm{H}$ and ${ }^{29} \mathrm{Si}$, respectively, for both $\mathrm{CP}$ and $\mathrm{MC}-\mathrm{CP}$ experiments. For the calibration curve (Fig. S2), samples with 
various reticulation rates (i.e., the synthesis was stopped at several durations and the solid recovered) were selected. For each sample, a quantitative single-pulse $\left(90^{\circ}\right)^{29} \mathrm{Si}$ MAS (recycle delay $500 \mathrm{~s}, \mathrm{~T}_{1}{ }^{29} \mathrm{Si}$ ) > $100 \mathrm{~s}$ for PSS at $7 \mathrm{~T}, 448$ transients per sample), a constant amplitude CP (3.5 ms contact time, 448 transients) and a MC-CP (20 loops of $2 \mathrm{~ms}, \mathrm{t}_{\mathrm{z}}$ of $2.5 \mathrm{~s}, 448$ transients) were recorded at MAS $5 \mathrm{kHz}$.

The MC-CP-DQ-SQ 2D NMR spectra of PSS-2 were recorded at static magnetic field of $11.7 \mathrm{~T}$ on an Avance Bruker NMR spectrometer in Versailles at MAS frequency of 5 or $5.5 \mathrm{kHz}$. At this field ${ }^{1} \mathrm{H}$ resonates at $500.1 \mathrm{MHz}$ and ${ }^{29} \mathrm{Si}$ at $99.3 \mathrm{MHz}$. The $\mathrm{SR} 26_{4}^{11}$ recoupling scheme was employed, which duration was set to $10 \mathrm{~ms} .{ }^{1} \mathrm{H} \mathrm{CW}$ decoupling was applied during the excitation and reconversion periods, while SPINAL decoupling was applied during the $t_{1}$ and $t_{2}$ evolution periods. For the initial MC$\mathrm{CP}$, the $\mathrm{t}_{\mathrm{z}}$ duration was set to $0.5 \mathrm{~s}$, the individual $\mathrm{CP}$ duration to $1.1 \mathrm{~ms}$ and the number of loops to 11 (total contact time of $12.1 \mathrm{~ms}$ ). The two-dimensional NMR spectra were recorded using the States procedure $^{[12]}$ to obtain phase sensitive spectra. All NMR spectra were analyzed using the Dmfit software. ${ }^{[13]}{ }^{1} \mathrm{H}$ and ${ }^{29} \mathrm{Si}$ isotropic chemical shifts are referenced to TMS.

\section{Quantification of the silicon species.}

To characterize POSiSils structure in general, the first solid-state NMR experiment to be run is a quantitative ${ }^{29} \mathrm{Si}$ single pulse MAS NMR spectrum to get information about the nature and the relative ratio of the various silicon species. In ${ }^{29}$ Si NMR literature Si atoms are denoted with a code consisting of a letter followed by a number. The letter symbolizes the amount of $\mathrm{O}$ atoms directly bound to the $\mathrm{Si}$ atom (M, D, T or $Q$ for the respective cases of $1,2,3$ or 40 atoms) while the number reflects the amount of those $\mathrm{O}$ atoms who in turn are bound to a second $\mathrm{Si}$ atom (Fig. 2b). Roughly three main types of signals are found on the ${ }^{29} \mathrm{Si}$ single pulse MAS NMR spectra of POSiSils (Fig. 2a): at around - 110 ppm 
are the $Q^{4}$ from the connected D4R unit, at $-100 \mathrm{ppm}$ are the $Q^{3}$ (i.e., Si-OH bonds from not connected D4R units). The $Q^{3}$ corresponds to unreacted cubes, its quantity gives the reticulation degree of the material. Finally, the D species (Si of the siloxane bridges) are located at higher isotropic chemical shifts (between 0 and $-22 \mathrm{ppm}$ ).

\section{a}

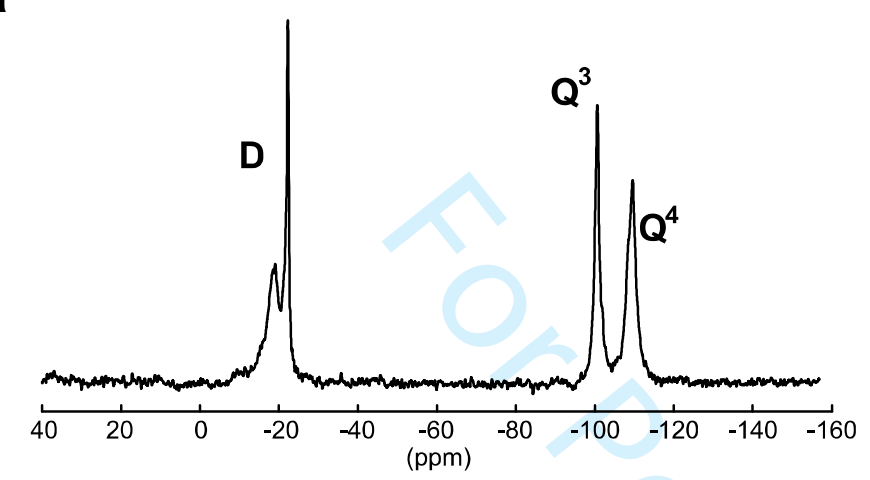

b

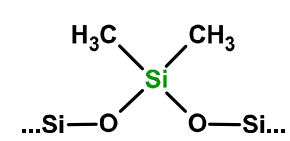

Si: D (0 - -22 ppm)

Si: $Q^{3}(-100 \mathrm{ppm})$

Si: $Q^{4}(-110 \mathrm{ppm})$
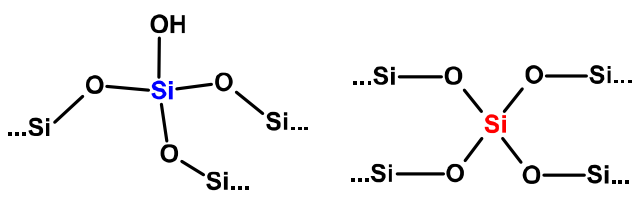

Fig. 2. (a) ${ }^{29} \mathrm{Si}$ single pulse MAS NMR spectrum of a PSS- 2 sample ( $57 \%$ connected) and (b) a schematic representation of the different ${ }^{29} \mathrm{Si}$ species present in the sample.

The $Q^{4}, Q^{3}$ and $D$ species have very long transversal $T_{1}$ relaxation time of about 130,160 and $50 \mathrm{~s}$ (at 11.7 T, these values are lower $7 \mathrm{~T}$, with $100 \mathrm{~s}$ for the $\mathrm{Q}^{3}$ ), respectively, hence to get a quantitative ${ }^{29} \mathrm{Si}$ NMR spectrum, the minimum recycle delay between two acquisitions has to be set to $800 \mathrm{~s}$ ( 5 times the longest $\mathrm{T}_{1}$ ), making the experimental time very long to get reasonable signal to noise ratio. To reduce this time, ${ }^{1} \mathrm{H} \rightarrow{ }^{29} \mathrm{Si} \mathrm{CP}$ experiment can be used (Fig. 3a) since $\mathrm{T}_{1}\left({ }^{1} \mathrm{H}\right)$ is orders of magnitude shorter $(<1 \mathrm{~s})$. 
For PSS-2, however, the local heterogeneity of the material makes the ${ }^{1} \mathrm{H} \rightarrow{ }^{29} \mathrm{Si} \mathrm{CP}$ response non-linear, as each type of silicon atom yields a different NMR response at different contact times (Fig. 3 for the $Q^{3}$ and $Q^{4}$ species). Because of this heterogeneity and because there is a lot of coupled protons, this material is favorable for the MC-CP experiment. ${ }^{[14 b]}$

The principle of the MC-CP NMR experiment is to break the initially long contact time into small contacts separated by repolarizing periods, preventing the decay of the signal due to $T_{1 \rho H}$ relaxation for long contact times, as clearly observed for the $Q^{3}$ species (Fig. 3). In the MC-CP, a plateau is reached for long total contact time (larger than $18 \mathrm{~ms}$ ). For such long total contact time, the relative intensity of the ${ }^{29} \mathrm{Si}$ resonances should thus reflects the number of each silicon species in the material (Fig. 3). This is confirmed by comparing the ${ }^{29} \mathrm{Si}$ single pulse quantitative NMR spectrum with the ${ }^{1} \mathrm{H} \rightarrow{ }^{29} \mathrm{Si} \mathrm{MC}$-CP spectrum recorded with total contact time of $20 \mathrm{~ms}$ that have similar relative intensity between the species (see Fig. S1). Note that due to the excessively long $\mathrm{T}_{1}\left({ }^{29} \mathrm{Si}\right)$ in POSiSils, the time to record a MC-CP NMR spectrum with reasonable signal to noise is significantly shorter than the time required to record a ${ }^{29} \mathrm{Si}$ single-pulse NMR spectrum. 

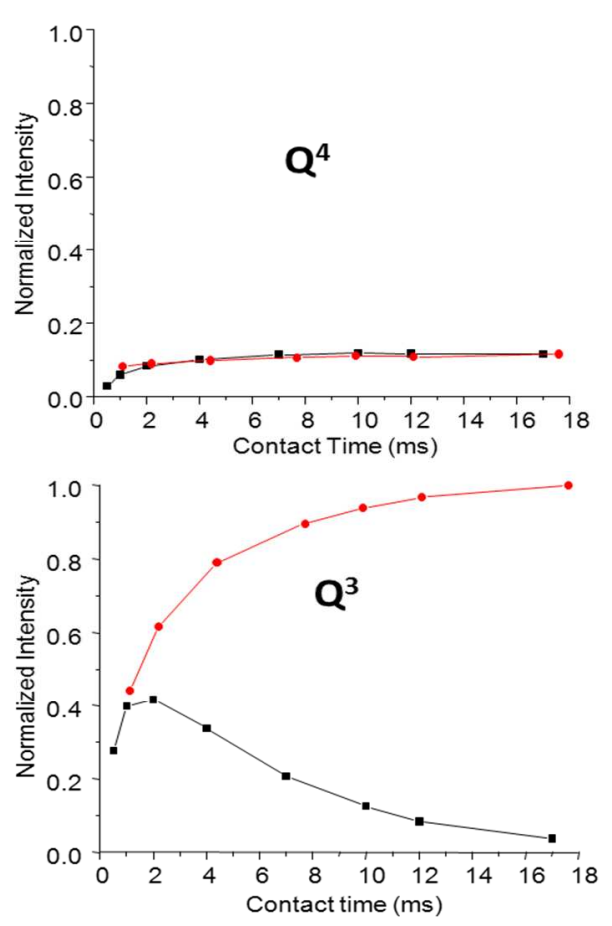

Fig. 3. Intensity of the ${ }^{29} \mathrm{Si} N \mathrm{NMR}$ signals of $\mathrm{Q}^{4}$ (top) and $\mathrm{Q}^{3}$ (bottom) species in PSS-2 recorded using ${ }^{1} \mathrm{H} \rightarrow{ }^{29} \mathrm{Si} \mathrm{CP}$ (black squares) and MC-CP (red circles) as a function of the total contact time duration. For the MC-CP, the individual contact time was set to $1.1 \mathrm{~ms}$ and the $t_{z}$ delay to $2.5 \mathrm{~s}$.

This experiment was further validated by recording ${ }^{1} \mathrm{H} \rightarrow{ }^{29}$ Si constant amplitude $\mathrm{CP},{ }^{1} \mathrm{H} \rightarrow{ }^{29} \mathrm{Si} \mathrm{MC}-\mathrm{CP}$ and ${ }^{29} \mathrm{Si}$ single pulse NMR spectra for PSS-2 at various stages of reticulation, i.e., containing various $Q^{3} / Q^{4} / D$ ratios. The relative line areas of all resonances of four different PSS- 2 materials acquired by CP and $\mathrm{MC}-\mathrm{CP}$ are plotted against the relative line areas of the same resonances acquired by a single-pulse NMR experiment (see Fig. S2). The latter, being fully quantitative, represents the theoretical value. While the CP data deviates strongly from the diagonal ( $y=0.9802 x, R^{2}=0.6918$ ), a much better agreement is obtained with the MC-CP data $\left(y=1.009 x, R^{2}=0.9618\right)$. Therefore, these findings indicate that the MC-CP can provide nearly quantitative results in a significantly reduced experimental time compared to direct ${ }^{29} \mathrm{Si}$ observation. 


\section{2. $2 \mathrm{D}^{29} \mathrm{Si}^{29}{ }^{29} \mathrm{NMR}$.}

Recording 2D ${ }^{29} \mathrm{Si}^{29}{ }^{29} \mathrm{Si}$ double-quantum single-quantum (DQ-SQ) NMR spectra at natural abundance ${ }^{29} \mathrm{Si}$ is very challenging due to the low abundance of ${ }^{29} \mathrm{Si}-{ }^{29} \mathrm{Si}$ spin pairs $(4 \% \times 4 \%=0.16 \%)$, and long ${ }^{29} \mathrm{Si}$ recycle delays. Here, the presence of protons makes the experiment easier as i) an initial ${ }^{1} \mathrm{H} \rightarrow{ }^{29} \mathrm{Si} \mathrm{CP}$ significantly enhances the initial ${ }^{29} \mathrm{Si}$ polarization and ii) the $\mathrm{T}_{1}\left({ }^{1} \mathrm{H}\right)$ is quite short $(<1 \mathrm{~s})$ in these materials allowing short repetition delays.

Two types of interactions can be used to generate ${ }^{29} \mathrm{Si}$ homonuclear NMR spectra: the scalar ${ }^{29} \mathrm{Si}-\mathrm{O}-{ }^{29} \mathrm{Si}$ coupling and the dipolar ${ }^{29} \mathrm{Si}{ }^{29} \mathrm{Si}$ interaction. The former goes through the chemical bonds while the latter goes through space, i.e., does not require chemical bond. J-coupling based NMR spectra can be obtained for example by refocused INADEQUATE scheme. ${ }^{[15]}$ The drawback of the experiment is the systematic absence of diagonal signals, inherent to the pulse sequence, which is lacking important information for the structural characterization of POSiSils. Therefore, we chose dipolar-based sequences. There are several schemes to recouple the homonuclear ${ }^{29} \mathrm{Si}$ dipolar-dipolar coupling, among which the SR2 $6_{4}^{11}$ (Fig. 4), ${ }^{[16]}$ which was selected because it was proven efficient for zeolites. ${ }^{[17]}$ This recoupling requires the application of a RF field of 6.5 times the MAS frequency. Therefore, it only works for low MAS frequency (5 or $5.5 \mathrm{kHz}$ in this study) in standard MAS NMR probes, corresponding to recoupling powers of $32.5-35.75 \mathrm{kHz}$ for long recoupling times (typically $10 \mathrm{~ms}$ ). Note that ${ }^{1} \mathrm{H}$ continuous wave decoupling is applied during the recoupling periods to prevent signal decay due to the ${ }^{1} \mathrm{H}_{-}{ }^{29} \mathrm{Si}$ dipolar interaction. 
a
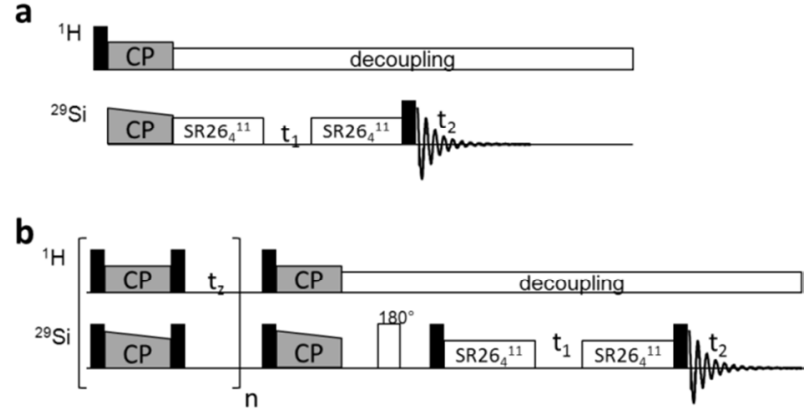

Fig. 4. Pulse sequences of the (a) CP-DQ-SQ and (b) MC-CP-DQ-SQ. In both experiment the excitation and reconversion of the ${ }^{29} \mathrm{Si} \mathrm{DQ}$ coherence are achieved by applying the SR2 $6{ }_{4}^{11}$ scheme. ${ }^{1} \mathrm{H}$ continuous wave decoupling is applied during the recoupling periods, while ${ }^{1} \mathrm{H}$ SPINAL-64 decoupling is applied during the $t_{1}$ and $t_{2}$ periods. Black rectangles are $90^{\circ}$ pulses.

This experiment generates a $2 \mathrm{D}^{29} \mathrm{Si}^{29} \mathrm{Si} \mathrm{DQ}-\mathrm{SQ} \mathrm{NMR}$ spectrum (Fig. 5 black) composed of diagonal peaks, if two silicon atoms with the same chemical shifts are close in space, and pairs of crossdiagonal peaks, if two silicon atoms with distinct chemical shifts are close in space. The indirect (vertical) dimension is twice as large as the direct dimension. The ${ }^{29}$ Si MAS NMR spectrum expands over ca 110 ppm (i.e., ca $11 \mathrm{kHz}$ at $11.7 \mathrm{~T}$ ), therefore, it expands over $220 \mathrm{ppm}(22 \mathrm{kHz}$ ) in the vertical dimension. Because the MAS frequency is small $(5 \mathrm{kHz})$, it is not possible to synchronize the indirect with the MAS frequency, hence the appearance of spinning sidebands in the indirect dimension. Shearing the DQ dimension to a SQ dimension does not help, because the isotropic peaks and the spinning sidebands are interleaved. Another spectrum was therefore recorded at $5.5 \mathrm{kHz}$ MAS frequency (Fig. 5 red), in which only the spinning sidebands shift positions, allowing unambiguous distinction between the spinning sidebands and the isotropic peaks. Another possibility would have been to use a higher MAS frequency of $8 \mathrm{kHz}$, that would have shifted the spinning sidebands between the peaks of interest. However, this would require the application of $52 \mathrm{kHz} \mathrm{RF}$ field on the ${ }^{29} \mathrm{Si}$ channel (in addition to the $\mathrm{CP}$ and the continuous decoupling) for long time, which is demanding on the probe. Hence, we chose to keep the 
spinning rate low. And then, for easier deciphering of the ${ }^{29} \mathrm{Si}^{29} \mathrm{Si}$ SQDQ MAS NMR spectra in this work, the spinning sidebands were removed from the spectra shown in the next section.

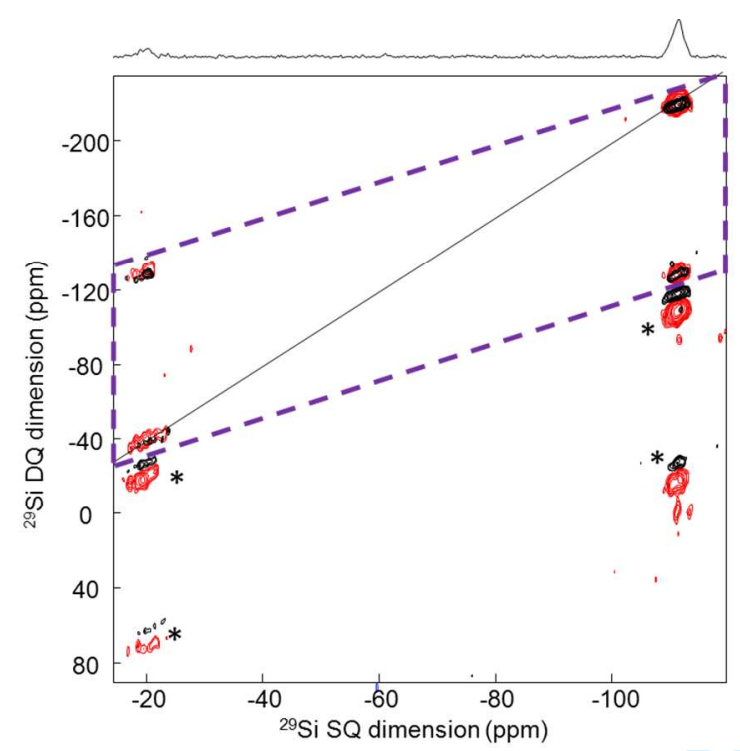

Fig. 5. ${ }^{29} \mathrm{Si}-{ }^{29} \mathrm{Si} \mathrm{DQ}-\mathrm{SQ}$ NMR correlation spectra of a PSS-2 sample ( $57 \%$ connected) recorded at MAS rate of $5 \mathrm{kHz}$ (black spectrum) and $5.5 \mathrm{kHz}$ (red spectrum). The spinning sidebands, marked by a star, change positions in the indirect dimension between the two MAS rates. Correlations inside the dashed rectangles are the peaks of interest. The thick line has a slope of 2 . Each spectrum requires $140 t_{1}$ slices with 32 transients each (almost 4 hour experiment).

While this experiment was efficient for PSS- $1,{ }^{9}$ when applied to PSS-2, we noted the absence of the $Q^{3}$ signal (Fig. 6a) when 8 ms were used as contact time for the initial CP block. Because all species have different $\mathrm{CP}$ build-up curves (see previous section), it is difficult to excite properly and simultaneously all resonances. Therefore, we replaced the initial CP block by a MC-CP block (Fig. $4 \mathrm{~b}$ ). This generates a $2 \mathrm{D}^{29} \mathrm{Si}^{29} \mathrm{Si} \mathrm{DQ}-\mathrm{SQ}$ NMR spectrum in which all resonances exhibit enough intensity to become detectable, including that of the $Q^{3}$ species (Fig. 6b). The gain of the important structural information is obtained at the expense of significantly increased experimental time ( 4 hours for when using a normal initial CP block vs 2 days for a MC-CP block). However, contrary to the ${ }^{29} \mathrm{Si} 1 \mathrm{D}$ experiments that have to be fast to guide the synthesis procedure (hence the use of the MC-CP), this 
experiment is only performed in the final compounds. Measurement time is therefore less critical than accurate structural information present on the NMR spectrum.
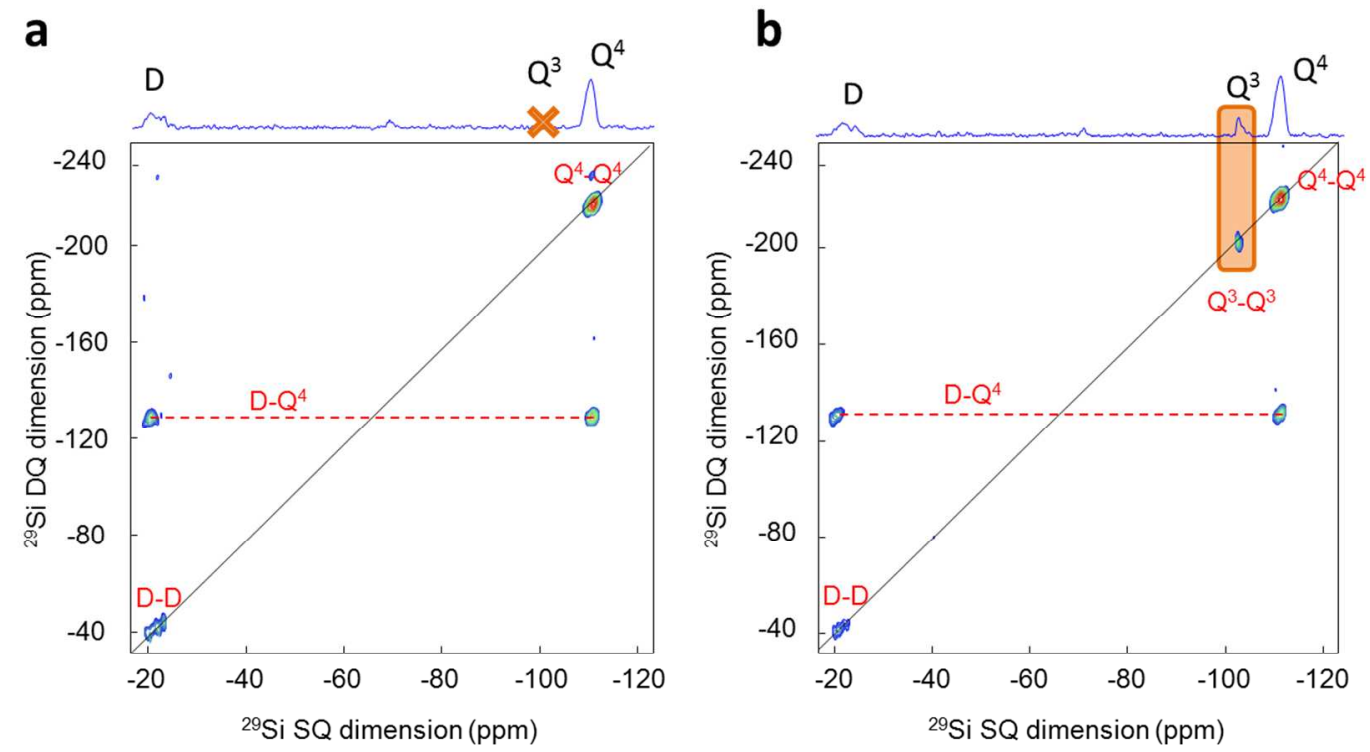

Fig. 6. ${ }^{29} \mathrm{Si}-{ }^{29} \mathrm{Si} \mathrm{DQ}-\mathrm{SQ}$ NMR correlation spectra of a PSS-2 sample (57\% connected) recorded with an initial (a) CP block (8 ms contact time) and (b) MC-CP block (12.1 ms total contact time separated by repolarization periods of $1 \mathrm{~s})$. In (b), the signal of the $Q^{3}$ species is recovered. Each spectrum requires $140 t_{1}$ slices with 32 transients each (four hours experiment when using CP block, 2 days experiment when using the MC-CP block).

This experiment is a first key step for understanding the structure of these polymers. However it needs to be complemented by other sets of information provided by other characterization methods, and computation modeling. A full structural characterization methodology of PSS-2 will be reported in a forthcoming work. ${ }^{10}$

\section{Conclusions}


We presented a set of NMR experiments that are suitable to investigate the structure of the new family of inorganic copolymers POSiSils. The ${ }^{1} \mathrm{H} \rightarrow{ }^{29} \mathrm{Si}$ MC-CP MAS NMR experiment was shown to provide close to quantitative data for these materials, in an experimental time much faster than direct ${ }^{29} \mathrm{Si}$ measurement. It is useful to determine the degree of reticulation of POSiSils and to extract the $Q^{4} / D$ ratio, which gives indication about the length of the silicone linkers. In a second part, the spatial proximities between the silicon in the polymer were revealed by the ${ }^{29} \mathrm{Si}^{29} \mathrm{Si} \mathrm{MC}-\mathrm{CP}$ DQ-SQ MAS NMR despite the highly contrasted ${ }^{29} \mathrm{Si}$ relaxation times in PSS-2. These latter was key so that all the proximities in this heterogeneous material appear on the 2D NMR spectrum. We expanded the NMR tool-box for NMR Crystallography, which will help to describing accurately structures of POSiSils.

\section{Acknowledgments}

CM thanks the Institut Universitaire de France (IUF) for financial support. FT, SS, PV and JAM thanks the support of KU Leuven, FT, FS and CMC the support of both CNRS and the University of Versailles S.Q.Y. The PHC Tournesol program number 35605TG supported the collaboration between both research groups.

\section{References}

[1] R. K. Harris, R. E. Wasylishen, M. J. Duer, 'NMR Crystallography', John Wiley \& Sons Ltd., United Kingdom, 2009.

[2] F. Taulelle, Fundamental Principles of NMR Crystallography.; 'NMR Crystallography' John Wiley \& Sons Ltd., 2009, 245.

[3] C. Martineau, "NMR Crystallography: Applications to inorganic materials", Solid State Nucl. Magn. 
Reson. 2014, 63-64, 1.

[4] S. E. Ashbrook, D. McKay, Chem.Commun. 2016, 52, 7186.

[5] C. Martineau-Corcos, Current Opinion in Colloid \& Interface Sci. 2018, 33, 35.

[6] Special Issues on NMR crystallography: a) CrystEngComm 2013; b) Solid State Nucl. Magn. Reson. 2015; c) IUCRJ Acta Crystallogr. C 2017.

[7] T. Pawlak, M. Jaworska, M. J. Potrzebowski, Phys. Chem. Chem. Phys. 2013, 15, 3137.

[8] D. M. Dawson, R. F. Moran, S. E. Ashbrook, J .Phys. Chem. C 2017, 121, 15198.

[9] S. Smet, S. Vandenbrande, P. Verlooy, S. Kerkhofs, E. Breynaert, C. E. A. Kirschhock, C. MartineauCorcos, F. Taulelle, V. van Speybroeck, J. A. Martens, Chem.-Eur. J. 2017, 23, 11286.

[10] S. Smet et al., in preparation.

[11] a) A. Nevzorov, J. Magn. Reson. 2011, 209, 161; b) J. Raya, B. Perrone, J. Hirschinger, J. Magn. Reson. 2013, 227, 93.

[12] D. J. States, R. A. Haberkorn, D. J. Ruben, J. Magn. Reson. 1982, 48, 286.

[13] D. Massiot, F. Fayon, M. Capron, I. King, S. Le Calvé, B. Alonso, J. O. Durand, B. Bujoli, Z. Gan, and G. Hoatson, Magn. Reson. Chem. 2002, 40, 70.

[14] a) R. L. Johnson, K. Schmidt-Rohr, J. Magn. Reson. 2014, 239, 44; b) F. Saïdi, F. Taulelle, C. Martineau, J. Pharm. Sci. 2016, 105, 2397.

[15] S. Cadars, J. Sein, L. Duma, A. Lesage, T. N. Pham, J. H. Baltisberger, S. P. Brown, L. Emsley, J. Magn. Reson. 2007, 188, 24.

[16] P. E. Kristiansen, M. Carravetta, W. C. Lai, M. H. Levitt, Chem. Phys. Lett. 2004, 390, 1.

[17] D. H. Brouwer, R. J. Darton, R. E. Morris, M. H. Levitt, J. Am. Chem. Soc. 2005, 127, 10365. 


\section{Solid-state NMR tools for the structural characterization of POSiSils: ${ }^{29} \mathrm{Si}$ sensitivity improvement with MC-CP and $2 \mathrm{D}^{29} \mathrm{Si}^{29} \mathrm{Si} \mathrm{DQ}-\mathrm{SQ}$ at natural abundance.}

Sam Smet, Pieter Verlooy, Fadila Saïdi, Francis Taulelle, Johan A. Martens, Charlotte Martineau-Corcos*
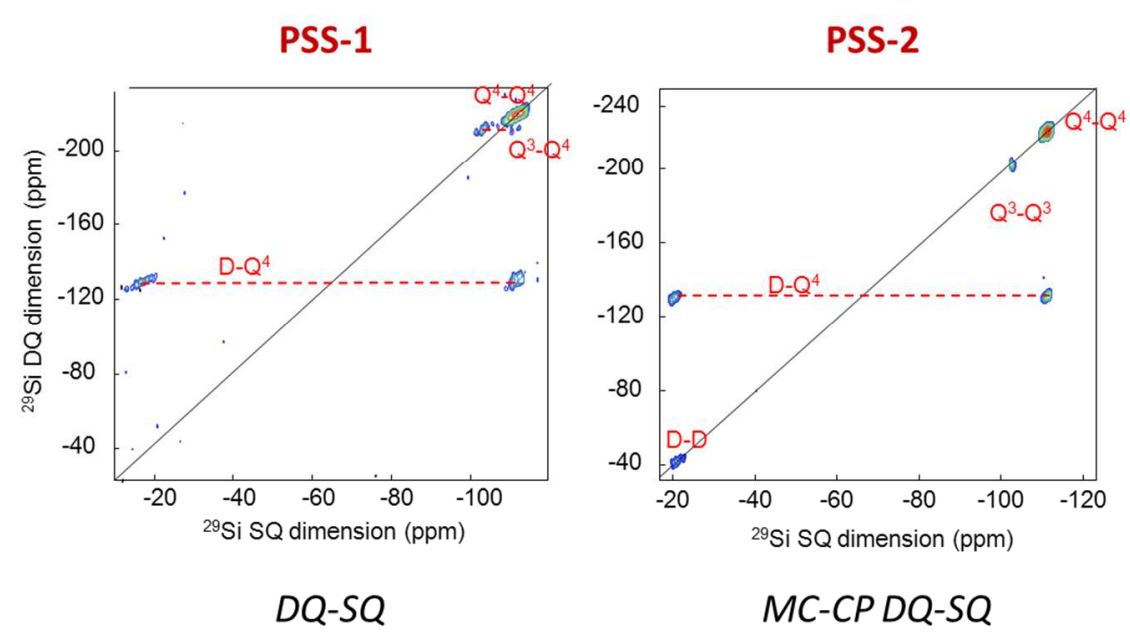

The NMR tool-box for NMR Crystallography of POSiSils is expanded: the ${ }^{1} \mathrm{H} \rightarrow{ }^{29} \mathrm{Si} \mathrm{MC}-\mathrm{CP}$ provides nearly quantitative information about the various silicon species in the materials, while the $2 \mathrm{D}^{29} \mathrm{Si}^{29} \mathrm{Si} \mathrm{MC}-\mathrm{CP}$ DQ-SQ provides information about the connectivity between the species. These data will help understanding the structure of this new class of materials. 